Article available at nttp://Www.parasite-journal.org or nttp://ax.dol.org/10.1051/parasite/200108s2054

\title{
ULTRASTRUCTURAL CHARACTERISTICS OF NURSE CELL-LARVA COMPLEX OF FOUR SPECIES OF TRICHINELLA IN SEVERAL HOSTS
}

\author{
SACCHI L.*, CORONA S. ${ }^{*}$, GAJADHAR A.A.** \& POZIO E.***
}

Summary :

The nurse cell-larva complex of nematodes of the genus Trichinella plays an important role in the survival of the larva in decaying muscles, frequently favouring the transmission of the parasite in extreme environmental conditions. The ultrastructure of the nurse cell-larva complex in muscles from different hosts infected with T. nativa (a walrus and a polar bear), T. spiralis (horses and humans), T. pseudospiralis (a laboratory mouse) and T. papuae (a laboratory mouse) were examined. Analysis with transmission electron microscope showed that the typical nurse cell structure was present in all examined samples, irrespective of the species of larva, of the presence of a collagen capsule, of the age of infection and of the host species, suggesting that there exists a molecular mechanism that in the first stage of larva invasion is similar for encapsulated and non-encapsulated species.

KEY WORDS : Trichinella nativa, T. spiralis, T. pseudospiralis, T. papuae.

\section{INTRODUCTION}

T The nurse cell-larva complex of nematodes of the genus Trichinella is quite unique in nature (Despommier, 1998). It plays an important role in the survival of the larva in decaying muscles, frequently favouring the transmission of the parasite in extreme environmental conditions. The objective of the present work was to study the ultrastructure of the nurse celllarva complex in muscles from different hosts infected with four species of Trichinella, i.e., two encapsulated species (Trichinella spiralis and Trichinella nativa) and two non-encapsulated species (Trichinella pseudospiralis and Trichinella papuae).

\section{MATERIALS AND METHODS}

T the study material consisted of muscle samples infected with T. spiralis, T. nativa, T. pseudospiralis and T. papuae. The samples infected

\footnotetext{
* Department of Animal Biology, University of Pavia, Pavia, Italy.

** Canadian Food Inspection Agency, Saskatoon, Saskatchewan, Canada S7N 2R3.

**** Istituto Superiore di Sanità, Rome, Italy.

Correspondence: E. Pozio, Istituto Superiore di Sanità, viale Regina Elena 299, 00161 Rome, Italy.

Tel.: +390649902304 - Fax: +39064938 7065 - e-mail: pozio@iss.it
}

with $T$. spiralis were taken from three naturally infected horses originating from Poland, Romania and Serbia (Pozio et al., 1999a) and from humans, who acquired the infection for the consumption of horsemeat. Biopsies from human muscles were performed two months and 16 months after infection (Pozio et al., 2001). The samples infected with $T$. nativa were collected from a walrus (Odobenus rosmarus) from Canada and from a polar bear (Ursus maritimus) from the Svalbard Islands. The samples infected with $T$. pseudospiralis and $T$. papuae were taken from laboratory mice. The isolate of T. pseudospiralis originated from a raccoon dog from Caucasus (Russia), the Garkavi's isolate. The isolate of $T$. papuae was obtained from a naturally infected wild pig from Papua New Guinea (Pozio et al., 1999b). The ultrastructural morphology was studied using a Zeiss EM 900 transmission electron microscope (TEM).

\section{RESULTS}

Trep $\mathrm{n}$ the nurse cell, the endoplasmic reticulum had replaced myofilaments; vesicles, swollen mito1 chondria, and hypertrophic nuclei with nucleoli in the transcriptional phase were evident. Two months after infection, TEM micrographs of human muscles infected with $T$. spiralis revealed that the nurse celllarva complex was surrounded by a thin capsule of connective tissue (Fig. 1). Sixteen months after infection, the larva was surrounded by smooth and rough endoplasmic reticulum, numerous vesicles, ribosomes, Golgi complexes and hypertrophic nuclei in the transcriptional phase. The collagen capsule was observed to have thickened remarkably (Fig. 2).

The nurse cell in muscles of horses imported from Romania and Former Yugoslavia had a very thick capsule (average $22.7 \mu \mathrm{m}$ and $33.5 \mu \mathrm{m}$, respectively), suggesting that in both animals the infection was old. By contrast, the nurse cell of the horse imported from Poland had a thin capsule (average $18.7 \mu \mathrm{m}$ ), suggesting that this animal had acquired the infection recently. 


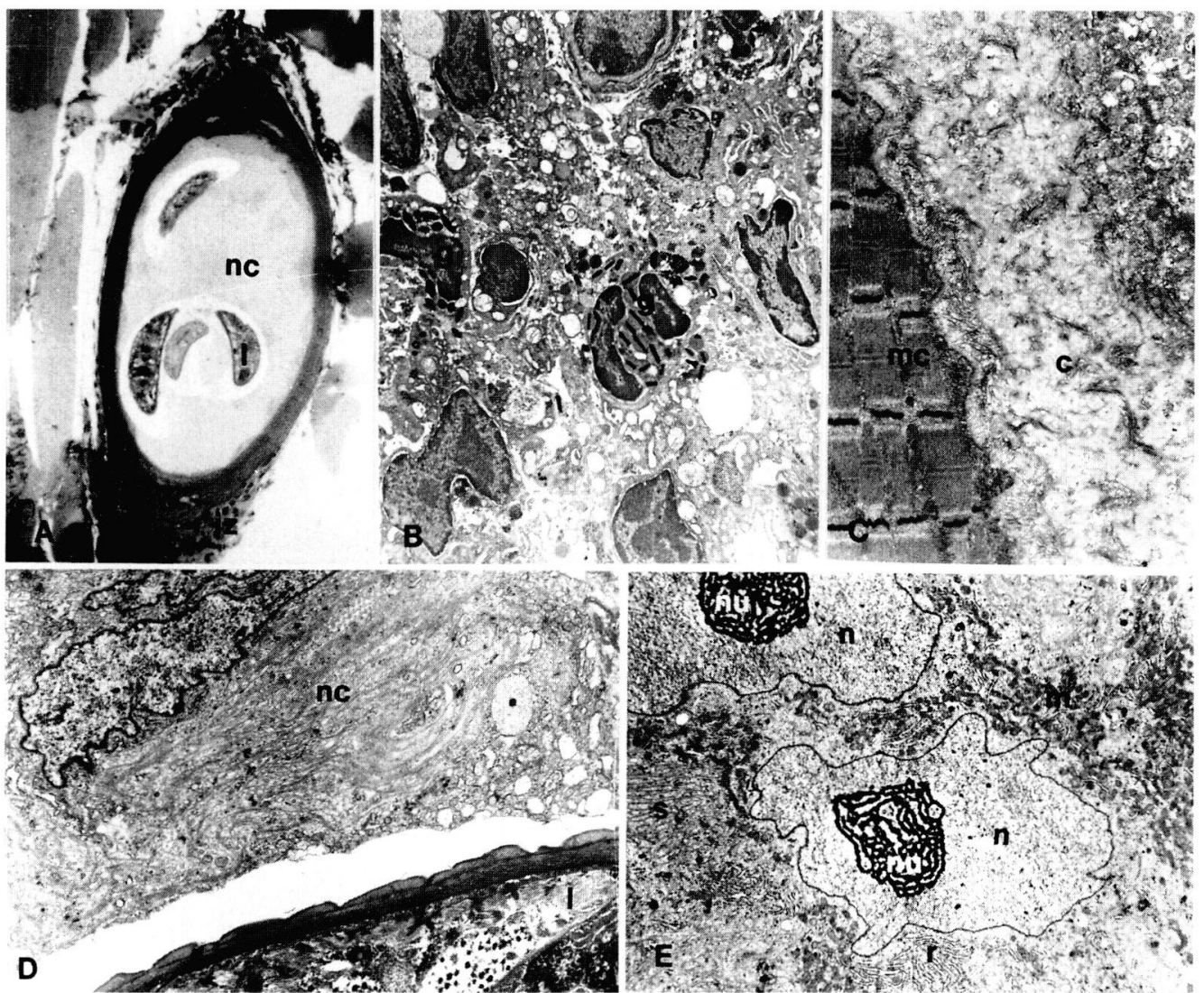

Fig.1. - Trichinella spiralis larvae in human muscles two months after infection. A) Transverse section of an encapsulated larva $(\times 960)$; B) transmission electron micrograph (TEM) of the inflammatory zone $(\times 5,500)$; C) TEM of the periphery of the capsule showing the thin collagen envelope ( $x$ $13,000)$; D) TEM of the nurse cell showing a large amount of smooth and rough reticulum, vesicles and Golgi complexes ( $x$ 14,000); E) TEM of a nucleus of the nurse cell in the trascriptional phase $(x$ 5500). $C=$ collagen capsule, $\mathrm{g}=$ granulocyte, $\mathrm{iz}=$ inflammatory zone, 1 = larva, $\mathrm{m}=$ mitochondria, $\mathrm{mc}=$ muscle cell, $\mathrm{nc}=$ nurse cell, $n=$ nucleus of the nurse cell, nu $=$ nucleolus, $r=$ rough reticulum, s = smooth reti culum
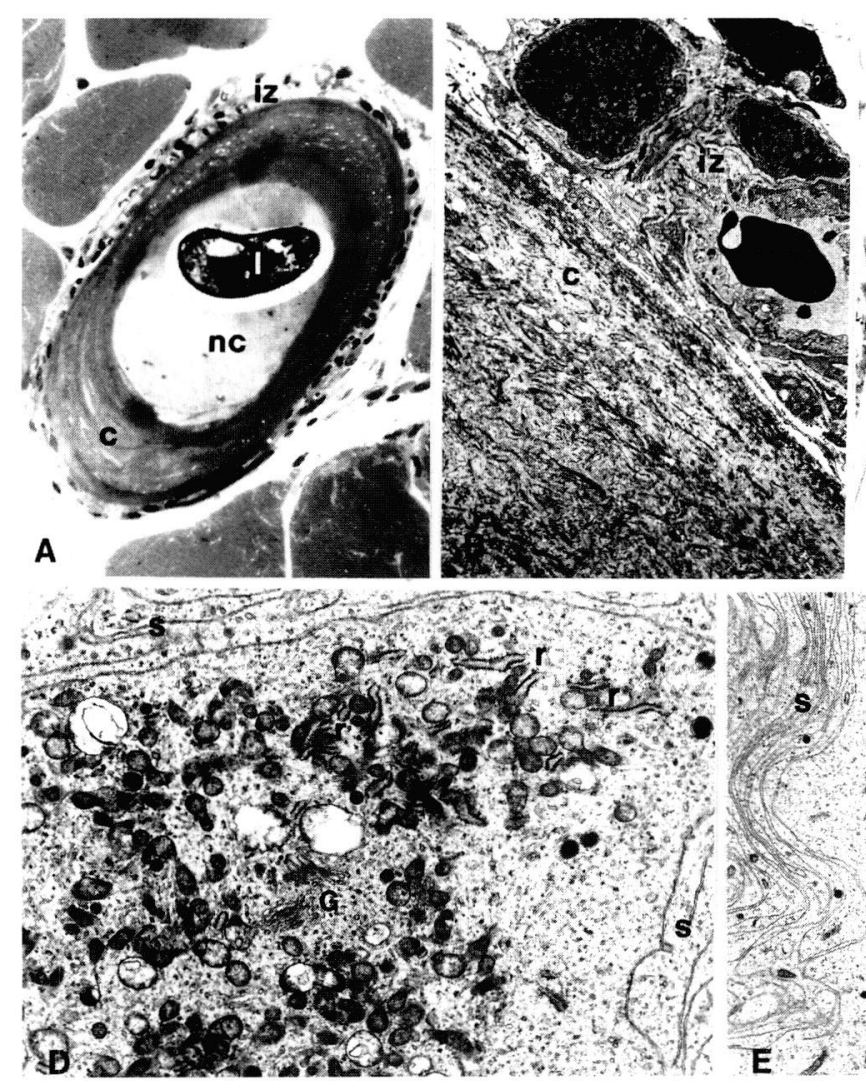

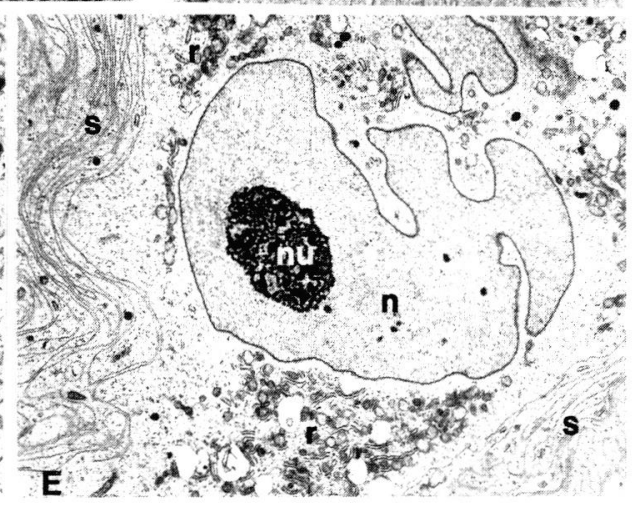

Fig. 2. - Trichinella spiralis larvae in human muscles 16 months after infection. A) Transverse section of an encapsulated larva. Note the thickness of the capsule $(\times 1,250)$; B) transmission electron micrograph (TEM) of the peripheral zone of the collagen capsule $(\times 9,700)$; C) TEM of the nurse cell-larva interface $(\times 9,700)$; D) TEM of a detail the nurse cell showing a large amount of smooth and rough reticulum, vesicles, and Golgi complexes ( $\times 14,000)$; E) TEM of a nucleus of the nurse cell in the transcriptional phase $(\times 5,500)$. $\mathrm{C}=$ collagen capsule, $\mathrm{G}=$ Golgi complex, iz $=$ inflammatory zone, 1 = larva, $\mathrm{nc}=$ nurse cell, $\mathrm{n}=$ nucleus of the nurse cell, $\mathrm{nu}=$ nucleolus, $\mathrm{r}=$ rough reticulum, $s=$ smooth reticulum. 
Fig. 3. - Trichinella nativa larvae in a polar bear (Ursus maritimus) muscle $(\mathrm{A}, \mathrm{B}, \mathrm{C})$ and a walrus (Odobenus rosmarus) muscle (D, E). A) Semi-thin section of an encapsulated larva. Note the remarkable thickness of the capsule ( $x$ 860); B) transmission electron micrograph (TEM) of the nurse cell-larva complex $(\times 5,500)$; C) detail of $\mathrm{B}$ showing the elaborate system of smooth endoplasmic reticulum, cisternae and degenerate mitochondria ( $\times$ 26,500); $\mathrm{D}$ and $\mathrm{E}$ ) TEM of the nurse cell-larva complex $(x$ 5,500), the typical nurse cell structure is destroyed in part for the bad preservation of the muscle sample. $\mathrm{C}=$ collagen capsule, $\mathrm{ci}=$ cisternae, $\mathrm{l}=$ larva, $\mathrm{m}=$ mitochondrion, $\mathrm{nc}=$ nurse cell, $\mathrm{s}=$ smooth endoplasmic reticulum.
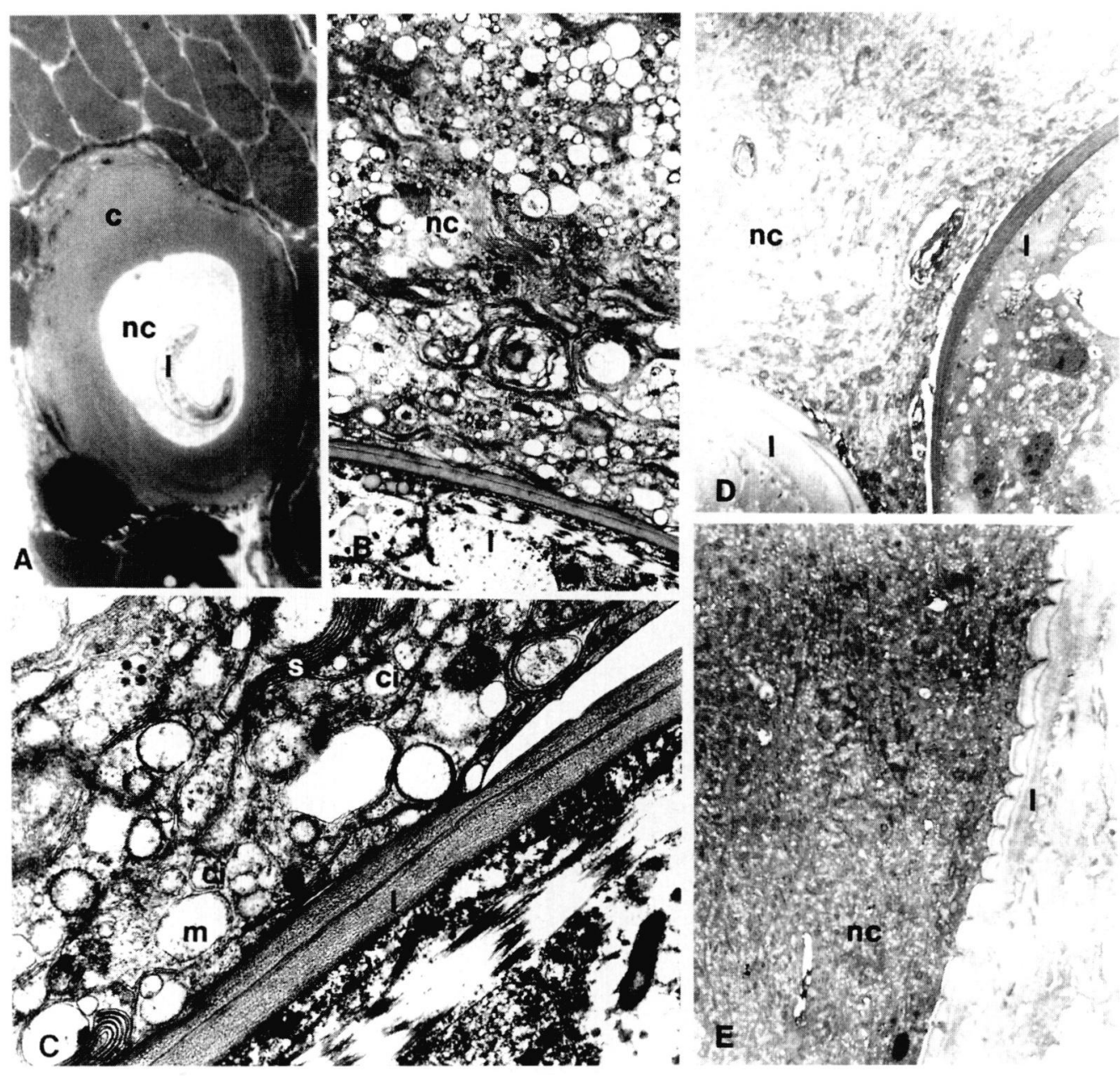

The thickest collagen capsule was that of $T$. nativa, observed in a polar bear (Ursus maritimus), in a walrus (Odobenus rosmarus) (Fig. 3) and in an arctic fox (Alopex lagopus) (data not shown).

TEM micrographs showed that both $T$. pseudospiralis (Fig. 4) and T. papuae (Fig. 5) larva lacked a collagen capsule; in both species, myofilaments were totally disarrayed, with clustering of mitochondria around the larva. Muscles infected with non-encapsulated larvae showed dramatic changes in the fibre architecture. The infective larvae were almost always located in the intracellular space, and no infiltration of inflammatory cells was observed around infected muscle fibres three months after the infection. A double-layered envelope covered the larval cuticle, and a host-derived dense plasmalemma-like layer appeared to be firmly attached to the host cell. In some cases, a nurse-cell-like structure was observed where the sarcomeres appeared to be replaced by a sarcoplasmic reticulum filled with cisternae, lamellar bodies, and ribosomes. An intense inflammatory reaction was observed around larvae that were apparently located outside the muscle cell, suggesting that larvae were moving among muscle cells.

\section{CONCLUSIONS}

1 EM analysis showed the presence of the typical nurse cell structure in all of the examined prese species of larva, the presence of a collagen capsule, of the age of infection and of the host species, suggesting that there exists a molecular mechanism that in the first stage of larva invasion is similar for encapsulated and non-encapsulated species. In encapsulated species, we observed a relationship between the thickness of the collagen capsule and both the age of infection and the Trichinella species. 


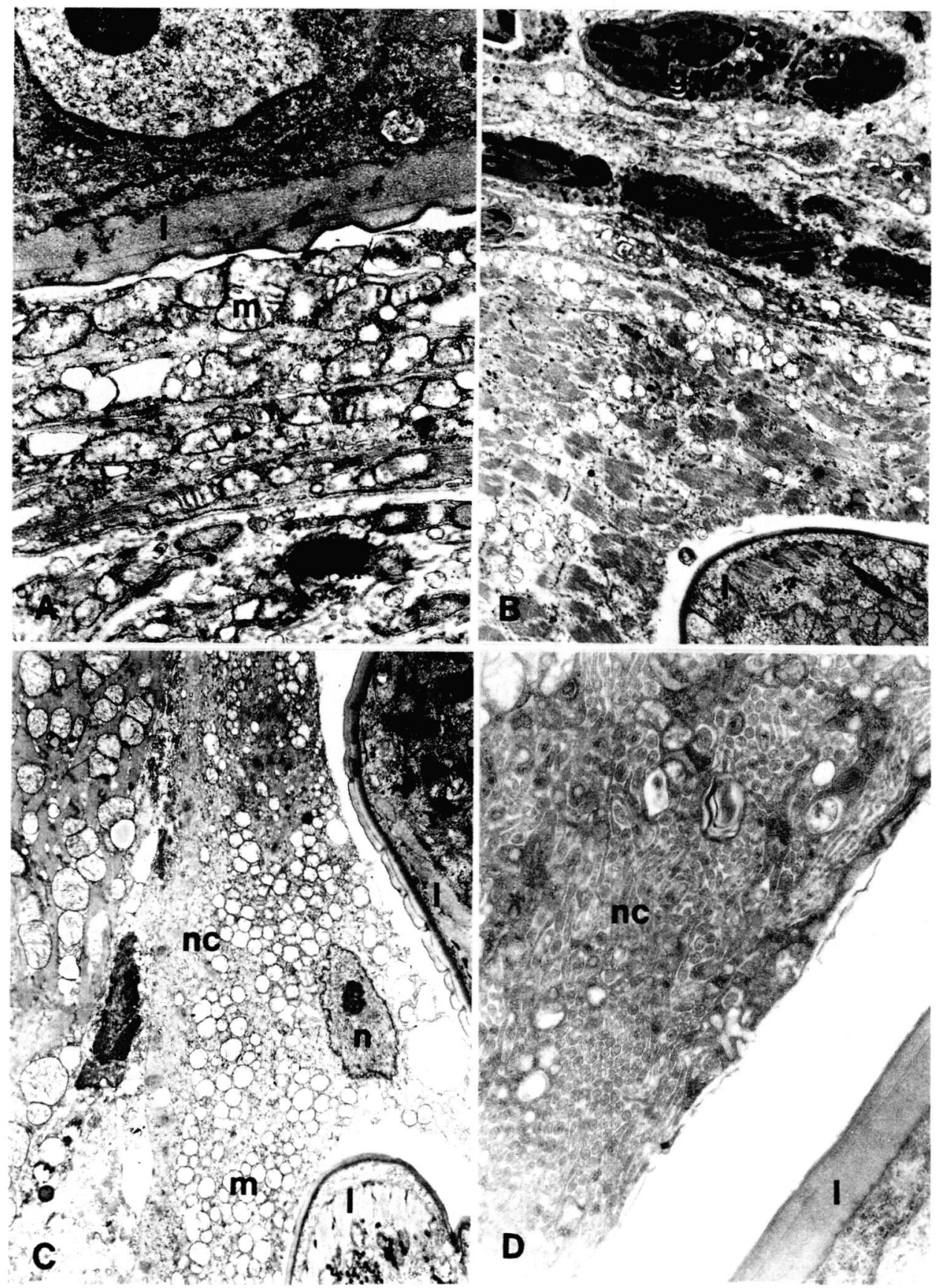

Fig. 4. - Trichinella pseudospiralis larvae in Swiss mouse muscles three months after infection. A) transmission electron micrograph (TEM) of a recently infected host muscle cell with the texture of the cell still partially conserved $(\times 20,000)$; B and C) TEM showing the disgregation of myofilaments and the concentration of mitochondria closed to the larval surface. The inner matrix of mitochondria is partially vacuolated $(\times 5,500)$; D) TEM of the nurse cell characterised by an elaborated system of the endoplasmic reticulum and cisternae $(\times 21,000)$. $\mathrm{G}=$ granulocyte, $\mathrm{l}=$ larva, $\mathrm{m}=$ mitochondria, $\mathrm{nc}=$ nurse cell, $\mathrm{n}=$ nucleus of the nurse cell. 
Fig. 5. - Trichinella papuae larvae in Swiss mouse muscles three months after infection. A) Semithin section of a larva showing the lack of the collagen capsule ( $x$ 1,400); B) transmission electron micrograph (TEM) showing a larva apparently located outside the muscle cell $(\times 5,500)$; C) TEM showing myofilament disaggregation and concentration of mitochondria close to the larva surface. Inflammatory cells (granulocytes) are present at the periphery $(\times 5,500)$; D) TEM showing a detail of the thick cluster of mitochondria surrounding the larva ( $\times 12,250)$; E) TEM of the nurse cell-larva complex $(\times 12,000)$; F) TEM of the nurse cell showing contractile elements replaced by sarcoplasmic reticulum $(\times 21,000) . G=$ granulocyte, $1=$ larva, $\mathrm{m}=$ mitochondria, $\mathrm{nc}=$ nurse cell.

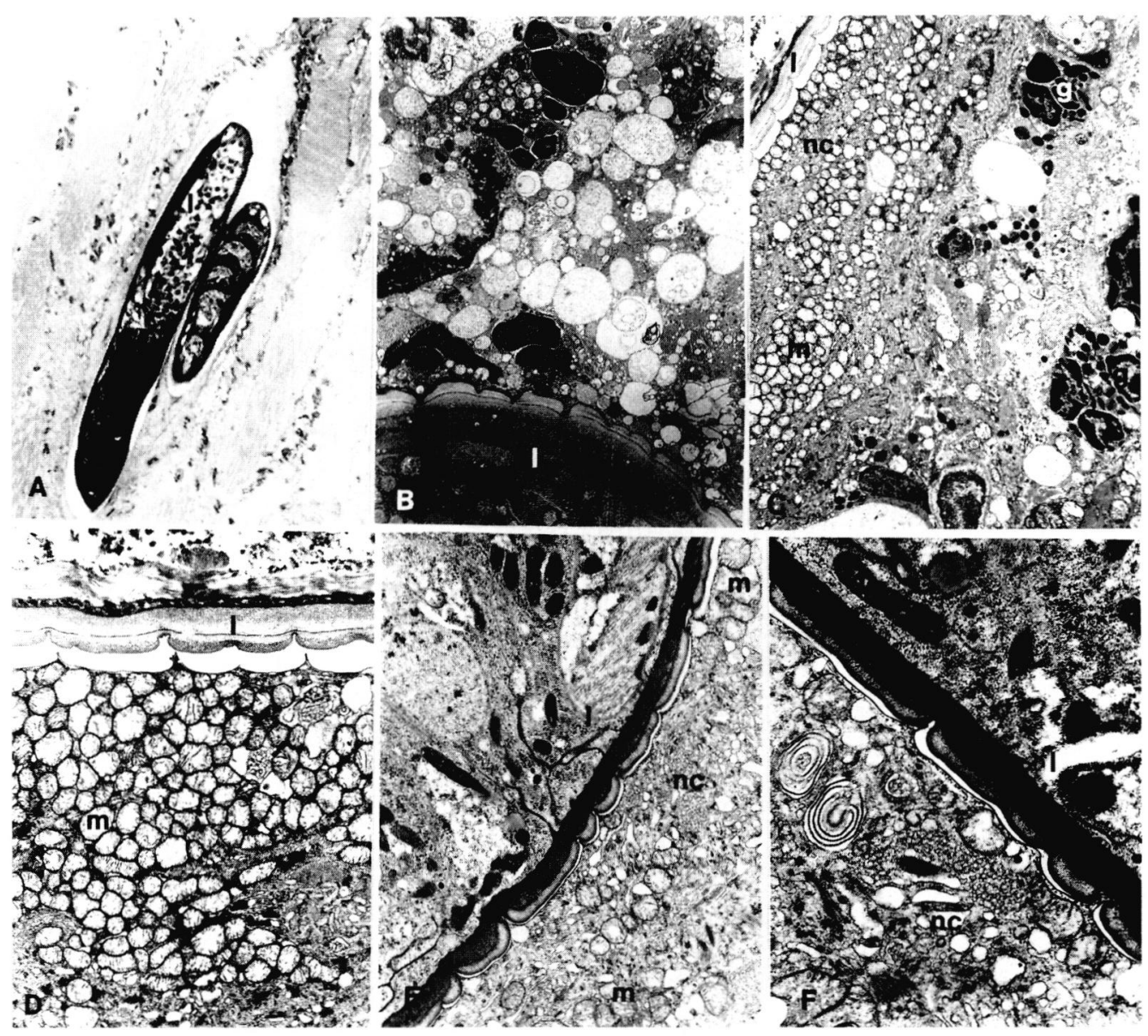

\section{ACKNOWLEDGEMENTS}

This work was made possible by the support received from the surveillance project on emer-

ging and re-emerging infectious diseases (Istituto Superiore di Sanità Art. 502/12, Ministry of Health of Italy).

\section{REFERENCES}

Despommier D.D. How does Trichinella spiralis make itself at home? Parasitology Today, 1998, 14, 318-323.

Pozio E., Paterlini F., Pedarra C., Sacchi L ., Bugarini R., GofFREDO E., \& BONI P. Predilection sites of Trichinella spiralis larvae in naturally infected horses. Journal of Helminthology, 1999a, 73, 233-237.

Pozio E., Owen I.L., La Rosa G., SAcchi L., Rossi P. \& Corona S. Trichinella papuae n. sp. (Nematoda), a new non-encapsulated species from domestic and sylvatic swine of Papua New Guinea. International Journal for Parasitology, 1999b, 29, 1825-1839.

Pozio E., Sacchini D., Sacchi L., Tamburrini A. \& Alberici F. Failure of mebendazole in treating Trichinella spiralis infection in humans at the stage of encapsulating larvae. Clinical Infectious Diseases, 2001, 32, 638-642. 